\title{
AC 2012-5528: CREATIVITY AND DESIGN: A GENERAL EDUCATION COURSE FOR ECE FRESHMAN
}

Dr. Robert Adams, University of Kentucky

Robert Adams is an Associate Professor of electrical and computer engineering at the University of Kentucky. He teaches several courses within the department and was the 2006 ECE Teacher of the Year. Most recently, he has redesigned the ECE 101 course: Creativity and Design in Electrical \& Computer Engineering. Adams' research interests and activities are in the areas of theoretical and applied electromagnetics.

Dr. Jens Hannemann, University of Kentucky

Mr. Lawrence Holloway, University of Kentucky

Lawrence Holloway, professor and Chair. Department of Electrical and Computer Engineering, University of Kentucky, Lexington, KY 40506. 


\title{
Creativity and Design: A General Education Course for ECE Freshman
}

\begin{abstract}
We have recently introduced a new Freshman engineering course, Creativity and Design in Electrical \& Computer engineering. The new course is designed to both fulfill the Creativity \& Arts (C\&A) requirement of the University's revised General Education curriculum, as well as to improve student retention from the Freshman year to the Sophomore year. This paper will review the challenges encountered in designing an engineering course to satisfy the C\&A requirements, the content of the course, sample student artifacts, and suggested modifications for future versions of the course.
\end{abstract}

\section{Introduction}

Like many similar programs, a goal of our University's Electrical \& Computer Engineering (ECE) Department has been to increase student retention from year-to-year, with particular emphasis on the transition from the Freshman to the Sophomore year. This challenge is being addressed through a number of initiatives, including modifications to the early portion of the student curriculum. A primary purpose of the latter modifications has been to increase faculty contact with Freshman ECE students from just one credit hour to a total of six credit hours in their first year at the University. In previous years, Freshman had only a one-credit ECE orientation course in the Fall of the year. We did not see these students again until the Fall of their Sophomore year. This significantly challenged our ability to introduce students to the exciting opportunities and events available through the ECE program and its associated student groups.

In the Fall of 2012 the ECE program made two significant changes to this situation. A three-credit core course on Logic Circuits was moved into the Spring semester of the Freshman year, and the formerly one-credit introductory course (EE101) was revised and extended to a three-credit course (also numbered EE101). This paper reports on the unique strategy pursued to accomplish the latter change to EE101.

At the same time that the ECE program was considering this change, the University's General Education Committee revised the GenEd curriculum. As part of this revision, students are now required to take 12 credit hours in the area of Intellectual Inquiry, with three of those credits falling in the area of Inquiry into Creativity and the Arts. The 12 required credits are divided into the following four areas:

- natural/physical/mathematical,

- social sciences,

- humanities,

- arts and creativity.

As part of this revision of the General Education curriculum, the GenEd Committee solicited proposals for new courses satisfying the requirements it delineated for each of these areas. 
In order to avoid increasing the total number of credit hours required by our students to earn a Bachelor's degree while simultaneously increasing the number of credits in the introductory ECE course from one to three, the new ECE course was designed to satisfy the requirements of the Arts \& Creativity area of the new GenEd curriculum. This was done with the ultimate goal of increasing student retention, and had the additional benefit of effectively reducing (by one) the total number of credits required to earn the ECE degree. The ability of such a course to improve student retention has been discussed extensively elsewhere ${ }^{1-4}$.

In addition to these advantages, this curricular modification is also consistent with the increasingly recognized importance of creativity and innovation in the modern economy ${ }^{5}$. It is also consistent with the generally recognized view that most a student's capacity for divergent thinking decreases as she progresses through an engineering curriculum ${ }^{6-10}$. While the reported change to our EE101 course is not necessarily expected to arrest such a decline, we think that it provides an important step in this direction.

\section{GenEd Course Template}

The University's General Education Committee provided the following guidance in a template for all new course proposals in the general area of Arts \& Creativity ${ }^{11}$ :

- Students will personally perform, produce, fabricate or generate an artifact or artifacts that demonstrate their engagement with the creative process (e.g. an object, product, installation, presentation, record of a performance etc.) either as an individual or as part of a collaborative. As part of this process, students should

- Define and distinguish different approaches (historical, theoretical, and methodological issues) to "creativity" as appropriate to the disciplinary practices specific to the subject, medium, or approach that informs a particular course.

- Apply the logic, laws, or constraints of the area of study (e.g, "out of the box" thinking, or the masterful, elegant treatment of given rules or forms).

- Demonstrate the ability to critically analyze work produced by other students in this course and in co-curricular events using appropriate tools. These analyses should utilize relevant information resources to incorporate historical, theoretical, and or cultural factors.

- Evaluate results of their own creative endeavors and, using that evaluation, reassess and refine their work.

The primary emphasis must be on active learning through student performance, expression, and/or production (what is known as "process focused" creativity). This emphasis should be documented through the number of assignments or class meetings devoted to this work, or through the grading mechanism for the final grade for the course.

\section{Creativity and Design in Electrical \& Computer Engineering (EE 101)}


Given this guidance from the General Education Committee and the related goals of the ECE program in increasing contact with and interest among Freshman students, the EE 101 course was expanded from one to three credits and re-titled as "Creativity and Design in Electrical and Computer Engineering.” The course content was completely revised in order to meet the complementary goals of fulfilling the GenEd Arts \& Creativity requirements while also providing significant hands-on opportunities for Freshman engineering students interested in the ECE major.

\section{EE101 Outcomes}

The outcomes for the new EE101 course closely follow those outlined above from the GenEd template:

Upon completion of EE101, students will have demonstrated the ability to:

1. Define and distinguish different approaches to creativity and creative inquiry.

2. Understand the significance and impact of creatively working within a set of externally imposed constraints, both from an historical and working perspective.

3. Understand the importance and role of ethical, professional, and cultural issues in the creative process.

4. Critically analyze the creative work of others using appropriate tools and criteria.

5. Evaluate results of their own creative endeavors and, using that evaluation, reassess and refine their work.

6. Recognize the importance of group collaboration, including oral and written communication.

\section{EE101 Schedule}

The new three-credit course was designed for a Tuesday/Thursday meeting schedule (1.5 hrs/meeting). Tuesdays' meetings consisted of lectures (by instructors and student groups), in-class exercises, quizzes, and exams. Thursday meetings were devoted to hands-on laboratory work.

The course schedule for Fall of 2011 was structured as follows:

\begin{tabular}{|l|l|l|}
\hline Week & Lecture (Tuesday) & Lab modules (Thursday) \\
\hline $1(8 / 24-8 / 26)$ & No lecture & Speaker + AM radio \\
\hline $2(8 / 29-9 / 2)$ & Intro to ECE & Speaker + AM radio \\
\hline $3(9 / 5-9 / 9)$ & Intro to creativity in science and eng. & Speaker + AM radio* \\
\hline $4(9 / 12-9 / 16)$ & The creative process I & Embedded computing \\
\hline $5(9 / 19-9 / 23)$ & The creative process II & Embedded computing \\
\hline $6(9 / 26-9 / 30)$ & The creative process III & Embedded computing \\
\hline $7(10 / 3-10 / 7)$ & Case studies in creativity I & Embedded computing* \\
\hline $8(10 / 10-10 / 14)$ & Case studies in creativity II & Signal processing \\
\hline $9(10 / 17-10 / 21)$ & Information literacy & Signal processing \\
\hline
\end{tabular}




\begin{tabular}{|l|l|l|}
\hline $10(10 / 24-10 / 28)$ & $\begin{array}{l}\text { Case studies - Student presentations I } \\
\text { (written and oral reports due) }\end{array}$ & Signal processing \\
\hline $11(10 / 31-11 / 4)$ & $\begin{array}{l}\text { Case studies - Student presentations II } \\
\text { (written and oral reports due) }\end{array}$ & Signal processing * \\
\hline $12(11 / 7-11 / 11)$ & $\begin{array}{l}\text { Case studies - Student presentations III } \\
\text { (written and oral reports due) }\end{array}$ & Student creations \\
\hline $13(11 / 14-11 / 18)$ & Image processing evaluations & Student creations \\
\hline $14(11 / 21-11 / 25)$ & Ethical and cultural considerations & No lab (Thanksgiving) \\
\hline $15(11 / 28-12 / 2)$ & Comprehensive review & In-class Exam \\
\hline $16(12 / 5-12 / 9)$ & In-class creativity exercise & Student creations \\
\hline $17(12 / 12-12 / 16)$ & Final Project Presentations (during Final Exam period) \\
\hline
\end{tabular}

* In-lab group presentations and reports are due for the indicated modules on these dates.

\section{Lecture Content}

The lecture portion of the course was given on Tuesdays. The first lecture (Week 2 above) provided basic orientation information for new ECE students. Lectures 2-5 reviewed the role of creativity in science and engineering, the importance of innovation in the greatest engineering achievements of the $20^{\text {th }}$ century ${ }^{12,13}$, neurological concepts underlying current understandings of creativity, convergent and divergent thought processes, the impacts of conventional education on creativity, relationships between intelligence and creativity, whether creativity can be measured, the relative importance of creativity in the future economy, creative process models, and techniques for encouraging creative thought. The next two lectures (6-7) looked at creativity case studies from various fields including visual art, music, mathematics, science, and engineering.

In preparation for Lectures 9-11, Lecture 8 provided an introduction to information literacy. The following lectures (Weeks 10,11,12) were given by student groups. For these presentations, groups were asked to select a creative development in an area related to Electrical \& Computer Engineering and provide both a written and oral report to the class summarizing the people and context behind the innovation.

Lecture 12 was the in-class evaluation of the final project reports from the Signal Processing Module (see below). Lecture 13 provided an introduction to the importance of ethical and cultural issues in engineering in general, and the specific issues introduced by technological innovation. The IEEE code of ethics ${ }^{14}$ was used as the ethical framework for this discussion. This was followed two weeks later (Lecture 15) with a brainstorming session during which students were divided into groups and asked to list the great engineering achievements that they expected to see in the next 100 years. This was followed by a discussion of the ethical and cultural challenges that such developments might pose to society and individuals. 
Finally, Lecture 14 (Week 15) provided a review of the material covered to date and was designed to prepare students for the exam given during the next meeting (a Thursday lab section).

\section{Laboratory Modules}

The Thursday meetings were reserved for laboratory (“hands-on”) work. This work was divided into four modules as follows:

1. Speaker and AM Radio Module

2. Embedded Computing Module

3. Signal Processing Module

4. Student Creation Module

Each of the first three laboratory modules was designed to both introduce students to some basic elements of Electrical \& Computer Engineering, while also providing significant opportunity for students working in teams (3-4 students/team) to creatively solve a design challenge within a given set of constraints. While students were not restricted in the ways in which they might be creative within a given module, each module lended itself to different types of creativity.

\section{AM radio}

In the first lab module, students were required to build devices which functioned as a speaker and as an AM radio receiver. This allowed us to discuss elements of electromechanics, electromagnetics, communications, and circuits. The creative opportunities provided by this module were largely in the physical design of the devices; the function was essentially fixed - students were required to construct artifacts that audibly received an AM radio stations. Students were, however, free to choose the materials and configurations used to assemble their speakers and AM receivers. The only restriction was that they could not use components of an existing speaker or receiver (and each group was given a diode). The student projects within this module were graded via peer evaluations. Each group received a peer evaluation of its speaker and receiver combination, with the each evaluation scoring both the functional quality and the creativity of each artifact.

\section{Embedded computing}

The second module introduced students to embedded computing using the Arduino ${ }^{15}$ (UNO) microcontroller. Within this module, students were given a brief introduction to the general area of embedded computing, followed by several well-defined tasks to perform using the Arudiuno controller. These introductory tasks were intended to teach students some of the basic skills required to use the controller for, potentially, more complicated tasks. After completing these pedagogical tasks, students were then given a list of available parts (e.g., LEDs, buzzers, buttons, temperature sensors, POTs, light sensors) and asked to come up with a creative device that performs some function using the Arduino. In this case, students were free to choose the device's function. To this end, student teams were encouraged to use a brainstorming technique (previously discussed in lecture) to determine a novel function that they would implement with the available parts using the Arduino as a platform. 


\section{Signal processing}

The third laboratory module introduced students to some basic signal processing concepts using the MATLAB ${ }^{16}$ image processing tool box. In addition to covering some topics from the area of image processing, this module also served to introduce students to the MATLAB computing environment (as well as Octave $^{17}$, a freely available clone of MATLAB), which they will see again in later courses in the ECE curriculum. Specific technical concepts introduced in this module included signals, systems, convolution, deconvolution, image and video representations, edge detection, and object identification/extraction. In addition to these specific concepts, students were shown where to find additional tutorials outlining additional capabilities of the audio and image processing toolboxes inside MATLAB.

As the culmination of this module, students were again asked to brainstorm to come up with and implement a creative image processing application using MATLAB's image processing toolbox for images and/or videos of their own creation. Students were given creative leeway in choosing both the function of their application, and the in the way they captured the images and/or videos to be processed (the latter providing opportunity for non-functional creativity). The creative student artifacts for this module were graded by requiring students to submit a presentation file (e.g., PowerPoint) that described their application. The submissions were subsequently shown (anonymously) to the class by the instructor, and students were asked to assess both the quality and creativity of the work produced by their peers.

\section{Student Creations}

The final laboratory module required student groups to propose and complete a project of their own choosing. Student groups were asked to either expand on one of the projects done earlier in the semester, incorporating feedback they had received, or to choose an alternative project of their choosing. The only constraints on the projects selected for this module were that (1) the groups' proposal should begin from a critical assessment of their previous laboratory projects (if appropriate), and (2) the proposed final project must, in the instructor's judgment, be feasible given available resources.

The Student Creations were presented during the class's two-hour Final Exam period (the students were not given a final exam). The projects were again evaluated in terms of overall quality and creativity. The evaluations were performed by the instructor, the class TA, and two other ECE faculty members, including the Chair of the department.

Descriptions, including videos of some fairly impressive student creations will be shown during the presentation of this paper. 


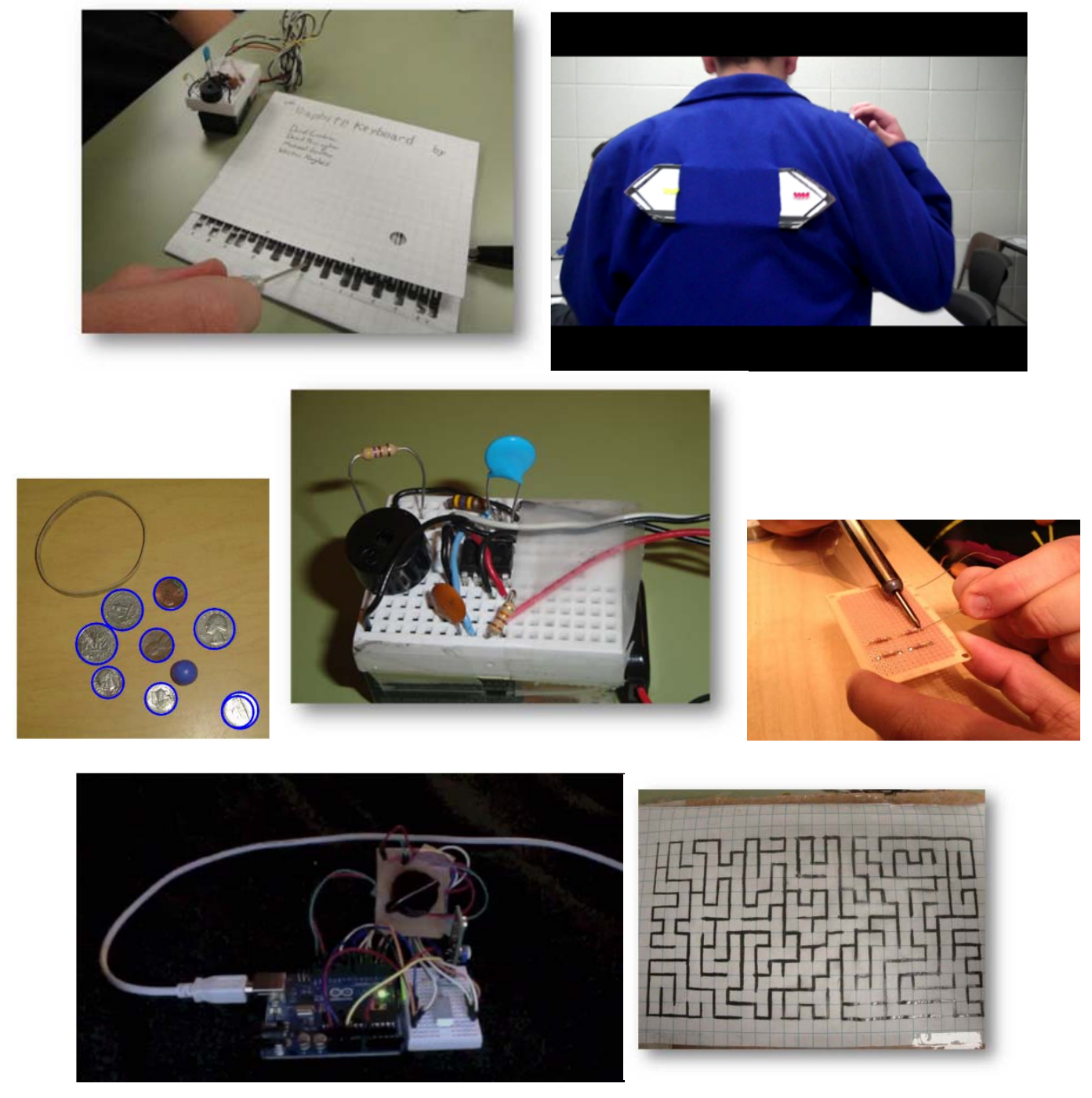

\section{Some Lessons Learned and Suggested Improvements}

The foregoing course was approved as described by the University's General Education Committee and it was implemented for the first time during the Fall Semester of 2011. There were three sections of the course offered, with each section containing approximately 30, 30, and 40 students. While our overall impression is that the course was successful, there are several things that will be improved during the next offering in Fall of 2012.

First, the course relied heavily on group activities. The group sizes ranged from two to four students. There was some complaining among a few of the students that their group members were not pulling their weight. While this did not seem to be a very significant issue, it is something we would like to improve upon in the future. In this direction, some 
of our colleagues have recommended beginning the semester with a team building session to help the group members build familiarity and trust with one another. We intend to incorporate such an exercise next Fall semester (Fall 2012). This will be accomplished by adding an additional, mandatory, one-time, two-hour meeting to the course schedule during the first or second week of the semester. This additional meeting will occur on-campus and will involve several team building exercises.

Another issue encountered during the semester was the significantly different programming capabilities of the Freshman students. Two of the laboratory modules (signal processing and embedded computing) required students to work with basic coding constructs. While this was trivial for some students, others had had no prior programming experience and found this to be quite difficult. We are currently considering incorporating another laboratory module (possibly in the area of alternative energy) that would not require any programming experience. It would then be possible to give students the opportunity to choose, for example, either the signal-processing or the alternative-energy module. With such a change, students would only be required to spend time programming in one of the four laboratory modules (instead of two of the four modules, as was required during this first implementation of the course).

A related comment raised by several students was their desire to have something related to the power area included in the course. If implemented, the change considered above would also address this issue.

A final change that will be implemented for Fall 2012 will be to ask students to clearly document the source of their ideas for the creative artifacts produced during each laboratory module. In a few cases during Fall 2011, it appeared as though some groups implemented projects found on the internet with limited creative input from themselves. We will try to reduce this type of behavior in the future by asking students to more carefully identify the creative aspects of their artifacts in their project proposals.

\section{Data and Conclusions}

In addition to emphasizing the importance of creativity and innovation in the field of engineering, a primary goal of this course was to improve student retention and interest in the ECE major. While we do not yet have data on its impact on student retention (the Spring semester has not yet started as of this writing; retention data will be available by the time of the presentation of this paper), we have seen a marked increase in Freshman participation in the IEEE student branch organization, the IEEE robot team, and the solar car team. We think this is an excellent indication that the overall efforts being made to increase student interest in ECE, of which our changes to EE101 are an important part, are having a positive effect. 
In addition to providing specific retention data during the presentation of this paper, student self-assessment data will also be available and included in the presentation.

\section{References}

1. J. W. Dally and G. M. Zhang, “A freshman engineering design course," Journal of Engineering Education, vol. 82, pp. 83-91, 1993.

2. J. Sullivan, "Exploiting design to inspire interest in engineering across the K-16 engineering curriculum,” The International Journal of Engineering Education, vol. 20, pp. 372-380, 2004.

3. Knight, D.W., L.E. Carlson, and J.F. Sullivan, "Improving engineering student retention through hands-on, team based, first-year design projects," Proceedings of the International Conference on Research in Engineering Education. Honolulu, HI, 2007.

4. M. Haungs, J. Clements, and D. Janzen, "Improving engineering education through creativity, collaboration, and context in a first year course,” ASEE Annual Meeting, Pittsburgh, PA, 2008.

5. Council on Competitiveness, Innovate America, 2005.

6. K. Kazerounian and S. Foley, "Barriers to creativity in engineering education: A study of instructors and students perceptions,” Journal of Mechanical Design, vol. 129, pp. 761-768, July 2007.

7. N. Genco, N., K. Hölttä-Otto and C. C. Seepersad, "An experimental investigation of the innovation capabilities of engineering students,” ASEE Annual Meeting, Louisville, KY, 2010.

8. B. Cooperrider, "The importance of divergent thinking in engineering design," ASEE Pacific Southwest Annual Conference, 2008.

9. J. Y. Lai, E. T. Roan, H. C. Greenberg, and M. C. Yang. (2008) "Prompt versus problem: Helping students learn to frame problems and think creatively". 2nd Design Creativity Workshop, Third International Conference on Design Computing and Cognition. Atlanta, GA, USA, June 2008.

10. P. Ludovice, L. E. Lefton, and R. Catrambone, "Improvisation for engineering innovation," ASEE Annual Meeting, Louisville, KY, 2010.

11. "Intellectual Inquiry - Arts \& Creativity: Toward Outcomes in Creative Endeavors," retrieved January 10, 2012, from www.uky.edu/UKCore/Documents/Templates/Creativity-arts.pdf.

12. G. Constable and B. Somerville, A Century of Innovation: The Engineering That Transformed Our Lives, Joseph Henry Press, 2003.

13. "Greatest Engineering Achievements of the $20^{\text {th }}$ Century," retrieved January 10, 2012, from http://www.greatachievements.org.

14. "IEEE Code of Ethics," retrieved January 10, 2012, from www.ieee.org/portal/pages/iportals/aboutus/ethics/code.html.

15. “Arduino,” retrieved January 10, 2012, from www.arduino.cc.

16. "MATLAB - The language of technical computing," retrieved January 10, 2012, from www.mathworks.com/products/matlab.

17. “Octave,” retrieved January 10, 2012, from www.gnu.org/software/octave. 